\title{
COMUNICAÇÃO
}

\section{TRATAMENTO DA ASCARIDÍASE POR MEIO DE HORTELÃ}

\section{Rubens Campos, Vicente Amato Neto, Antonio Augusto Baillot Moreira e Silvia Cristina Arantes}

Há no Brasil, presentemente, claro interesse no sentido de prestigiar a atividade terapêutica de plantas $^{2}$. A propósito, algumas investigações científicas estão em curso, mas é lícito reconhecer que o grande volume de utilizações tem nexo com crenças vigentes no âmbito de parte da comunidade. Tais concepções, componentes até da medicina caseira, por vezes, conduzem a comprovações cabais, amparadas em estudos bem conduzidos, advindo inclusive reconhecimento dos princípios ativos e respectivas sínteses. Todavia, impõe-se ressaltar $o$ respeito às pesquisas devidamente planejadas e executadas.

Nesse contexto, um exemplo é a preconização popular do chá de folhas de hortelã para a cura da ascaridíase. Como esse fato goza de expressivo prestígio, consideramos conveniente efetuar investigação a fim de esclarecer, com base em metodologia adequada, se a preparação referida possui realmente efetividade.

Tratamos 31 crianças, com idade de cinco a sete anos, parasitadas por Ascaris lumbricoides, conforme resultados de exames pouco antes realizados. Administramos, no período da manhã, durante cinco dias consecutivos, cerca de $150 \mathrm{ml}$ de chá açucarado de folhas de hortelã (Mentha spicata). Recomendamos jejum e alimentação no horário habitual de almoço. Para o preparo, diário, empregamos $10 \mathrm{~g}$, colocadas em um litro de água fervente, sendo de meia hora a duração da infusão, seguida de coagem.

Para avaliar os resultados, efetuamos três controles, 7, 14 e 21 dias depcis do término do perfodo de ingestão do chá, recorrendo aos processos de sedimentação espontânea em água e de Kato-Katz ${ }^{13}$. Consideramos que sucedeu cura quando se verificou a ausência de ovos de $A$. lumbricoides nessas diversas procuras.

\footnotetext{
Laboratório de Investigação Médica - Parasitologia, do Hospital das Clínicas, da Faculdade de Medicina da Universidade de Sáo Paulo, São Paulo, SP.

Endereço para correspondência: Prof. Vicente Amato Neto, Laboratório de Investigação Médica - Parasitologia, Av. Dr. Arnaldo 455, 01246-000 São Paulo, SP, Brasil.

Recebido para publicação em 02/03/93.
}

Só um êxito ocorreu e nas demais situações não detectamos sucessos ou diminuições dignas de registro das intensidades das infecções. Duas crianças tiveram diarréia passageira e eliminaram exemplares adultos do verme. No que tange a outras duas, não computadas, em virtude de cólicas abdominais deuse interrupção da tentativa de tratamento, mas de modo geral a tolerância ao chá mostrou-se satisfatória.

Portanto, pelo menos comoagimos, a preparação de hortelã afigurou-se imprópria quando desejada a cura da ascaridíase. Quiçá outra espécie da planta ou diferente forma de proceder coadunem-se com impressões populares. Não obstante, só opinamos a propósito do que fizemos.

Além do $A$. lumbricoides estavam, ocasionalmente, presentes diferentes cistos de protozoários ou ovos de helmintos. Não nos preocupamos em firmar conclusões atinentes a eles $\mathrm{e}$ apenas temos condições de citar que tricuríase quase sempre persistiu.

Fica assim registrada avaliação, com base em pesquisa suficientemente confiável, relacionada com convicção pública, digna de atenção e suscitadora de rigorosa comprovação.

\section{REFERÊNCIAS BIBLIOGRÁFICAS}

1. Amato Neto V, Corrêa LL. Exame parasitológico das fezes, $5^{\text {a. }}$ edição, Sarvier, São Paulo, 1990.

2. Campos R, Amato Neto V, Castanho REP, Moreira AAB, Pinto PLS. Tratamento da ascaridíase por meio do alho (Allium sativum). Revista do Hospital das Clínicas da Faculdade de Medicina da Universidade de São Paulo 15:213-215, 1990.

3. Katz N, Chaves A, Pelegrino J. A simple device for quantitative stool thick-smear technique in schistosomiasis mansoni. Revista do Instituto de Medicina Tropical de São Paulo 14:397-400, 1972. 
COMUNICAÇÃO

\title{
LIGHT EFFECT ON FEEDING OF FIRST INSTAR DIPETALOGASTER MAXIMUS IN XENODIAGNOSIS
}

\author{
M.N.A. Menezes, M.T.A. Garcia-Zapata, C.N. Castro, V.A. Soares and P.D. Marsden
}

\begin{abstract}
Observations of our laboratory colony of Dipetalogaster maximus over a period of ten years suggest that a smaller quantity of blood is being ingested by hungry first instar bugs ${ }^{13}$. Since in Mexico the majority of bugs are first instar of diurnal habit it was suggested that feeding might be related to light intensity ${ }^{2}$. The Table 1 shows that in five of six experiments where lots of $1001^{\text {st }}$ instar D. maximus were fed in the dark and in daylight conditions; the latter favoured blood ingestion. Observation five suggests that another ambiental factor is operating although temperature and humidity conditions were partially controlled. These results suggest that for optimal xenodiagnosis results with maximal feeding ${ }^{1^{\text {st }}}$ instar $D$. maximus should be allowed to feed in the light.
\end{abstract}

\begin{tabular}{|c|c|c|c|c|}
\hline \multirow{2}{*}{ Lot } & \multicolumn{2}{|c|}{ Light } & \multicolumn{2}{|c|}{ Dark } \\
\hline & before & after & before & after \\
\hline 1 & $7: 5$ & 41.5 & 7.8 & 24.4 \\
\hline 2 & 7.9 & 46.5 & 8.0 & 26.8 \\
\hline 3 & 7.5 & 47.9 & 7.3 & 28.9 \\
\hline 4 & 7.4 & 42.7 & 7.4 & 23.8 \\
\hline 5 & 7.5 & 53.6 & 7.4 & 58.8 \\
\hline 6 & 7.4 & 47.3 & 8.2 & 22.5 \\
\hline Mean & 7.6 & 46.6 & 7.7 & 30.9 \\
\hline
\end{tabular}

\section{REFERENCES}

1. Barreto AC, Prata A, Marsden PD, Cuba CC, Trigueiro CP. Aspectos biológicos e criação em massa de Dipetalogaster maximus (Uhler, 1894) (Triatominae). Revista do Instituto de Medicina Tropical de São Paulo 23:18-27, 1981.

2. Marsden PD, Cuba CC, Alvarenga NJ, Barreto AC. Report of a field collection of Dipetalogaster maximus (Uhler, 1894). Revista do Instituto de
Medicina Tropical de São Paulo 21:202-206, 1979.

3. Soares VA, Torno Cafasso O, Garcia-Zapata MT, Marsden PD. Biological aspects of Dipetalogaster maximus after prolonged laboratory cultivation. I. Eclosion time, fertility of eggs and the first nymphal feed after eclosion. Memórias do Instituto Oswaldo Cruz 81(suppl):164-165, 1986.

\footnotetext{
Núcleo de Medicina Tropical e Nutrição da Universidade de Brasília, Brasília, DF, Brasil. 